\title{
Methods of Entering Where Access is Restricted
}

\author{
Anna McLauchlan ${ }^{1}$ (D) Allyson F. Noble ${ }^{2}$
}

Received: 18 July 2018 / Accepted: 21 August 2019 / Published online: 20 September 2019

(c) The Author(s) 2019

\begin{abstract}
Where social occasions, in the context of nightclubs and music venues, are bounded, the space of the entrance is accomplished via regulation of attendees by workers. This regulation ensures: the venue stays within capacity; people have been invited or (if required) pay the fee; entry to 'undesirables,' such as drunks, is prohibited. This paper draws from experience of attending social occasions and being a doorperson to categorise and examine methods of entering where access is restricted. Often methods require attendees to engage in visible dialogue with the doorperson; where methods are invisible, attendees can circumvent access restrictions whilst a semblance of order is maintained.
\end{abstract}

Keywords Ethnomethodology $\cdot$ Methods $\cdot$ Entering $\cdot$ Social occasion $\cdot$ Locally produced authority $\cdot$ Door

\section{Introduction}

On a day-to-day basis people engage in a process of entering social occasions often through a doorway. Research has discussed the mechanics of the door and its influence on people's interaction (notably Johnson 1988; Latour 1992), including group interaction when negotiating revolving doors (Weilenmann et al. 2014), together with some of the methods to control licensed premises (Hobbs et al. 2002, 2003). The symbolic importance of the 'door' is also widely recognised (e.g., Metcalfe and Ferguson 2001; Simmel 1994). In the context of nightclubs and music venues in particular, a range of methods of entering are used and

Anna McLauchlan

anna.mclauchlan@strath.ac.uk; mclauchlan.anna@gmail.com

Allyson F. Noble

a.noble@hw.ac.uk

1 Civil and Environmental Engineering, University of Strathclyde, James Weir Building, Glasgow G1 1XJ, UK

2 Heriot-Watt University, International Academic City, PO Box 294345, Dubai, United Arab Emirates 
discussed by people managing and participating in social occasions. However, there has been limited academic attention to this topic. Following Weilenmann et al. (2014) this paper focuses on "the joint action between and within groups of door users" (2014: 124, emphasis in original). Rather than 'follow' people entering or exiting a building (Weilenmann et al. 2014) it examines how the process of 'entering,' and the space of the entrance, is accomplished through interaction of people working at and attending a social occasion.

Goffman (1963/1966: 18) identifies a 'social occasion' as “a wider social affair, undertaking, or event, bounded in regard to place and time and typically facilitated by fixed equipment". Thus, 'social occasions,' in their broadest sense, can range from the collective viewing of an outdoor tourist attraction such as a geyser to a national bingo championship. Access to places where people go to meet other people, as part of a social occasion, are often implicitly or explicitly restricted.

Where there is a prescribed boundary, the occasion can be said to take place in a 'venue'. In social occasions housed in a venue, transitional areas where people can enter or exit are required together with people-staff, performers, and organisersto manage the occasion or make it happen: this paper collectively refers to these people as 'workers'. Thus, the boundary generates a territory, in the sense identified by Sack (1986: 19), where one group could be viewed as delimiting and asserting "control over a geographic area".

Boundaries, and thus the related territory of the venue, can vary in their permanence. For example, a social occasion might happen in an existing building with relatively permanent entrances or exits (that is 'doors'), such as a bar or club. In the case of large social occasions, such as festivals, perimeter fences may be constructed for a short duration. In both cases these boundaries can vary in their permeability (or 'porosity,' Brunet-Jailly 2007), depending on the characteristics of the boundary and whether or to what extent workers' attempt to regulate attendees' movement.

If the occasion is contained in a venue with a structured largely impermeable boundary (i.e., relatively permanent walls), people who lend their presence to the occasion but have no active role in planning or management must engage in a process of 'entering,' most likely via a 'doorway'. Following Crabtree (2000: 2; also Neyland 2006) "space is not a worldly abstraction then, but embodied in, and integral to, the accomplishment of the activities that we do". There are three main forms of reasoning behind why a boundary would be used to restrict access in this context as Table 1 outlines. More than one form can be operative at any one time. ${ }^{1}$

\footnotetext{
${ }^{1}$ Social gatherings can have a border without charging a fee-screenings, gigs and occasions such as live TV or radio broadcasts can be 'free but ticketed'. Sometimes no actual ticket is required, whether this be paper, electronic or in some other form-for example, if someone attended a wedding without invitation it is likely to be noticed by the wedding party or friends and relatives (although obviously this depends on the size of the wedding, as the film Wedding Crashers 2005 satirises).
} 
Table 1 Reasoning why a boundary would be used to regulate, and thus restrict access-more than one form of reasoning can be operative at any one time

Reasoning

Abbrevi-

ated form of

reasoning

To ensure that the venue does not exceed its capacity (become over capacity) by containing more people than is desired by the owner or manager of the occasion (that is more than comfortable, or legally permissible by the state or both)

To, where applicable, exclude people who have not paid or been invited or both

Exclusion

To prohibit entry of undesirables, for example very drunk people or those whose style is Prohibit not coherent with the occasion

Where access is restricted, the doorperson represents themselves, but also tacitly represents the authority underpinning the occasion, be it the venue or the organisers. Individual circumstances, or desire, may run counter to the attendee yielding to that authority. The doorperson then has to balance their individual and the collective interest to decide how to respond to the attendee-how this happens in practice is analysed within this paper. This interaction depends on the reasoning behind why access is restricted. A locally produced authority, based on understandings of legitimate ways to behave, can be accomplished either via an attendee's acceptance of the restriction or their resistance to it.

A repetition of accepted conventions by the doorperson or doorpeople generates a sense of 'procedural fairness'. However, where treatment can be deemed 'unequal' (when a doorperson makes someone a guest on the spot or bars entry for no clear reason) the action privileges or diminishes the status of the attendee. The doorperson doing their job well requires much more than just following and interpreting a set of conventions (Raffel 1999, 2007), both the doorperson(s) and the attendee engage in a level of skilled interaction. Avoidance methods used by attendees must literally be visible to the doorperson-detection often requires both 'good' eyesight and the ability to 'read' or understand the action taken.

Attendees and workers can choose how to respond to access restrictions, as demonstrated in Table 2's column 'Response to the access restriction'. They can: accept; provide an exception; the attendee can pretend they have accepted; or openly disregard the restriction. Each of these broad responses is associated with particular methods, as listed in Table 2.

All of the broad categories are visible, both to the doorperson and the attendee, except for when an 'Attendee pretends they have accepted'; In this case, the methods only becomes visible when unsuccessful, that is, when it is observed by the doorperson and the attendee is prevented from entering. Pretending, 'faking,' or 'bluffing' is at the heart of many games, including card games such as Poker, where revealing the veracity of potential deception is an integral element. Desire to reveal deception may be why attendees often discuss their use of 'invisible' methods with others. This paper examines methods of entering in the order set out in Table 2, reviewing the potential responses of attendees and of the doorperson or doorpeople. First, to 


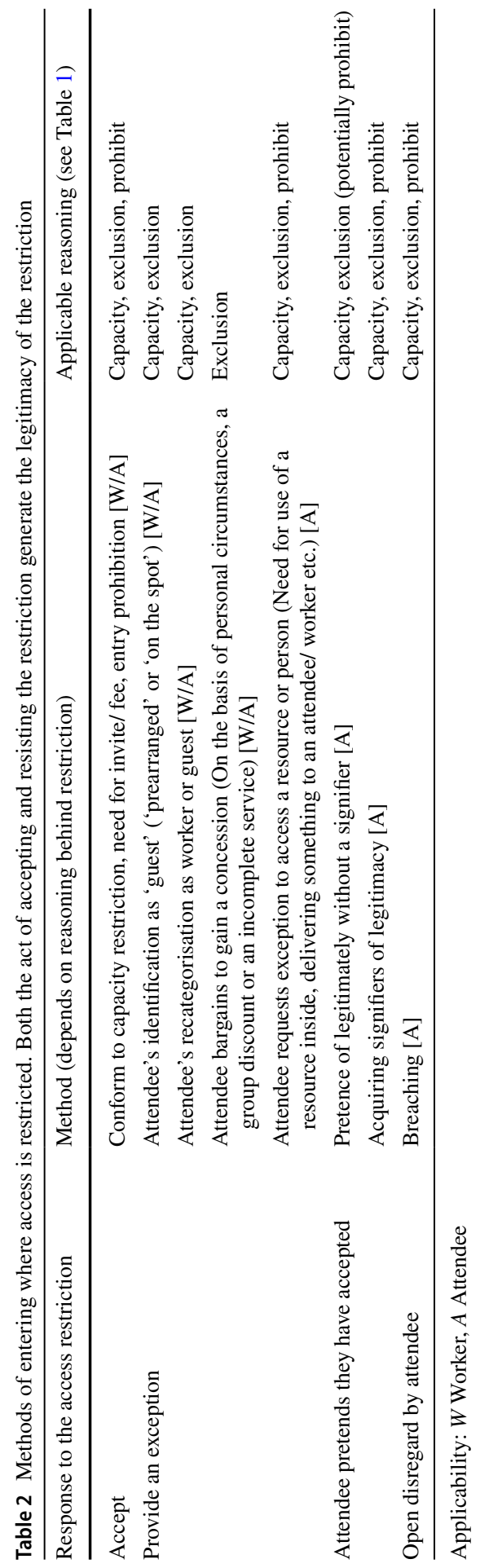


provide context on the use of the methods the case study of the all-night party is introduced in relation to the research approach.

\section{Research Approach and the All-Night (Mega) Party}

This paper draws from my (the first author's) experience of going to clubs and venues to see bands and/or DJs for over 20 years. ${ }^{2}$ In addition, for 2 years, I worked on the door of a nightclub most Friday nights, and have sporadically 'done the door' on numerous other occasions and locations within central Scotland. In both the role of attendee and doorperson, I have first-hand experience of using a variety of methods of entering. Thus, the approach taken is ethnomethodological in that it is concerned "with members' methods for making sense of the world" (Neyland 2006: 600; also Coulon 1995). There is a coherent set of approaches to attempt 'legitimate' and 'illegitimate' entrance that I have used, observed others use, and heard people talk about. $^{3}$

Much contemporary ethnomethodological practice focuses on observing members' methods and largely ignores the role of observer (the ethnomethodology practitioner). In this paper, the ethnomethodology practitioner (the first author) is central to the categorisation work taking place. Garfinkel, in his breaching experiments (1967/1984a), had some understanding of what might occur in advance of sending out his students to temporarily affect a breakdown of social order. Here, rather than breakdown or rupture, the experiment involved seeing what happens when the first author enforces a particular set of conditions as part of the situation being observed. The "Introduction" section of this paper has already foregrounded the analysis enabling the observed categories to be used to structure the discussion that follows.

That discussion is primarily anchored in the context of one occasion, the 'WSP VS CROC All Night Mega Party' or 'mega party' in Glasgow, Scotland, July 2011 - the third of three similar parties in this studio. WSP is an abbreviation of Winning Sperm Party, a non-profit collective that supports and promotes live performances by musicians. They also provide opportunities for musicians to record their

\footnotetext{
2 This relates to the time when this paper was first written-at the time of publishing this figure is somewhere in the region of 28 years.

${ }^{3}$ Use of the term 'legitimate' and 'illegitimate' refers to a locally produced form of illegitimacy rather than a broader frame. It should be noted that the overview this paper provides largely relates to occasions that take place at night, a time with carnivalesque qualities (in the sense of Bakhtin 1994), which arguably may sanction behaviour otherwise 'off-limits'. Also, this paper is informed by actions and accounts from a European (largely UK) and North American perspective.
} 
music, with releases taking the form of physical records, tapes and CDs but also as downloads normally available without charge online. Musicians working with WSP retain the recording rights to their music. ${ }^{4}$ Similarly, CROC, the short form name of Croc Madame versus Croc Monsieur, at the time of the mega party had been putting on DIY events in Glasgow in venues and flats for over 3 years.

Clearly, access is restricted even before the occasion: exclusion arises when people are not in the 'right' social circle, on the mailing list, not invited on social media or are confronted by a language that's unintelligible or deemed inappropriate. ${ }^{5}$ For example both 'You Don't Masturbate' and 'Fem Bitch Nation' played at the mega party, arguably such visceral sounding names are chosen to generate a reaction and potentially will put some people off. As Malbon (1999, following Goffman 1963) in an extended study of clubbing notes, there are 'entry qualifications': “The door becomes merely the last of many pre-clubbing tests of belonging, most of which are self-posed" (Malbon 1999: 67).

The mega party was the third party organised by WSP at a practice studio (normally used by bands to rehearse) in an industrial estate North West of Glasgow city centre-CROC had not contributed to the previous two parties. As the venue was (partially) sound proofed and surrounded by businesses that operated during the day rather than residential housing, the party could go on all night with limited risk of complaints about noise. People had to make a very conscious decision to attend because this site was not normally a venue, and, in contrast to city centre locations, ${ }^{6}$ was remote from other bars and clubs. Attending the mega party arguably required commitment. Figure 1 provides the layout of the practice studio-people begin the process of entering via the double doors at the lower part of the image that open into the 'Common Area'.

\footnotetext{
${ }^{4}$ Making music freely (or cheaply) available is in keeping with a do-it-yourself (DIY) ethos; similarly, WSP events are a relatively low price in comparison to those put on by commercial promoters. Despite this 'alternative' stance, the performance set up conforms to a 'standard' where performers are separated from the audience and elevated on low stages (see Fintoni and McLauchlan 2018 for a discussion of different arrangements).

5 Thanks to Barry Burns for this observation.

${ }^{6}$ Glasgow's zoning policy means that there is a concentration of bars in the city centre with a large number in Sauchiehall Street in particular which parallels the situation in Manchester as reported in Hobbs et al. (2002).
} 


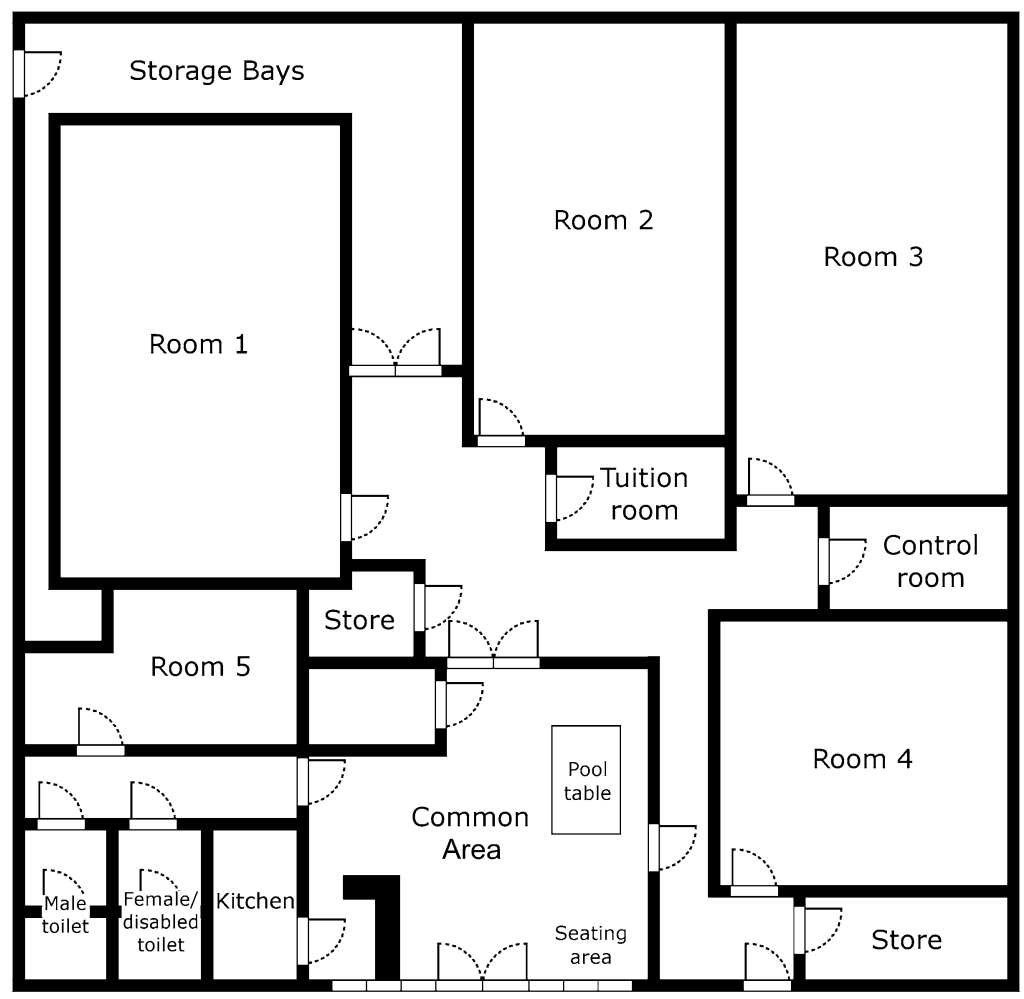

Fig. 1 The layout of the practice studio-people begin the process of entering into the Common Area via the double doors at the lower part of the image

There is only one open entrance/exit to the studio-a double door; the double door and the front wall of the practice studio were made of glass. ${ }^{7}$ This glass panelling made it possible to see outside from inside and vice versa. In the first party the double door was fully open and people (including attendees) passed a till where fees were collected. However, no one checked to see whether or not attendees had paid, therefore the fee could be avoided by just walking in. In all of the parties, when people paid a fee their hands were marked with the WSP stamp, Fig. 2.

\footnotetext{
${ }^{7}$ Although there was a fire escape door to the right of the main door this was alarmed and therefore is not considered 'open'.
} 
Fig. 2 The WSP stamp. In all of the parties, when people paid a fee their hands were marked with this stamp

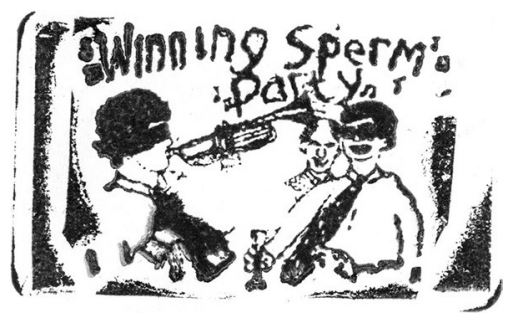

For the second and third parties one of the doors was closed and a board put up. This meant people had to walk past the till—a table blocked part of the entrance so that only 1-2 people could pass at a time. On both these occasions other workers took the payments and stamped attendees' hands and I checked to see whether or not attendees had stamps to indicate whether or not they had paid in. As such my role could be described as 'complete participant,' involved in and shaping interaction (Gold 1958).

As a way to analyse the methods of entering, this paper now largely recounts my experience of being a participant observer whilst doing the door at this, the third, WSP party in this studio. It was a Saturday evening in July 2011 after a sunny day; I began at 7.45 p.m. and stood in roughly the same spot until 3 a.m. the next morning. I chose not to have breaks because being there consistently enabled me to identify legitimate 'returners,' such as smokers, who had previously paid to get in. ${ }^{8}$ Staff changeovers provide a good opportunity for first-time enterers to claim they are returners. Therefore, my continued visibility through the glass-panelled doors restricted the viability of certain methods of avoiding the fee.

The layout of the studio and the presence of the doorpeople reinforce a social understanding that payment is required. Clearly, I was committed to the idea that people should pay, and this commitment resulted in the 'flushing out' of a wide range of methods of entering. Importantly, doorpeople may not be committed either to the occasion or its organisers as demonstrated by accounts of them syphoning money from takings. Interestingly, this activity was talked about openly, as with fee avoiders who brag of their ability to circumvent the entrance fee.

I was interested in how people might respond to my action. ${ }^{9}$ The following day I wrote up an account of my experience. That account was read by the second author and, through a collective process of discussion and analysis, parts of that account were used to inform this paper. My desire to analyse entering and fee avoidance

\footnotetext{
8 The potential for people to be entering a venue more than once during an evening calls into question whether the 'entering' found in the title of this paper should be changed to "passing" in the sense employed by Garfinkel and Stoller (1967-1984). Particularly since the smoking ban (enacted in Scotland in 2006) people may often enter venues a number of times which requires them to continually 'pass' as attendees. This did change firstly with the popularity of electronic cigarettes but soon these, and also the vapes that came after, were largely outlawed in many enclosed venues.

9 Whilst living in Toronto in Canada in 1998-1999 I undertook two performances where I waited in one location for an extended period of time. I have knowledge of this as an art practice and have participated in others' performances using this approach, for example as part of Romany Dear's work in Market Gallery, Nov-Dec 2011.
} 
leads to a question about this paper. In Garfinkel and Stoller's (1967/1984) study of Agnes, Garfinkel acknowledges that they were both 'passing' with each other: Agnes was passing as a woman and Garfinkel as a competent professional. Just as attendees brag of their fee avoidance activity, this paper could be understood as an elaborate form of bragging by 'making visible' my fee avoidance detecting skills.

The studio's location in an industrial estate, rather than a street, meant it was free from onlookers. The car park formed a transitional area, where those that had already entered could go out and smoke or just hang out-mixing with those that had yet to go in for the first time. Thus, the warm evening and the relative privacy of the outdoor area extended the party into the car park. Often boundaries do not contain all action associated with a site although circumstances may differ. Peace camps at the perimeter of military establishments provide a contrasting example. In that case, people in the peace camp are likely to have opposing views to military or other staff inside. Whereas, at the mega party, there was arguably some coherent expression of community both inside and immediately outside the practice studio. As discussed below, this outdoor party also formed an important strategic (but still partially visible) space for those aiming to avoid the fee.

Three out of five practice rooms in the venue were used-in total 22 bands played. This figure was higher than the other parties (although both the first and second parties had more than ten bands playing). ${ }^{10}$ Seeing one band in a bar or club (perhaps with two to three others as support) would normally cost from $£ 3$ to $£ 14$. Larger venues, such as Glasgow's Scottish Exhibition and Conference Centre, can charge $£ 70$ to see one main act. At $£ 5$, the party was very low priced particularly considering the duration (from 8 p.m. until 4.30 a.m.) and it was BYOB (bring your own bottle/booze).

At the first party where the door regulation was lax roughly 200 people paid. Whereas in the second and third parties where my presence resulted in strong door regulation approximately 400 paid, double the figure of the first. The parties happened at different times of year, and other contextual factors, such as the success of the former party, may explain the higher numbers of people. However, there was likely substantial fee avoidance at the first party.

Such avoidance differs from the 'price setting' (Bifo 1979) undertaken by collectives identified under the banner of the Italian autonomous movement, or linked contemporary attempts to reduce prices charged in shops (the process of 'bargaining' explored in Garfinkel 1967/1984b). In those examples, the authority being negotiated is associated with a state sanctioned legal system. The high rate of use of the avoidance methods (described below) coupled with the low overall cost suggests that the desire to not pay had a complex relationship to the entrance fee. Following Table 2's outline, the methods of entering are now set out in detail.

\footnotetext{
10 One band played at a time, but if a band over-ran their $15 \mathrm{~min}$, in some cases, they overlapped with the next band. DJs played in the Common Area (Fig. 1) —when the first bands were on the DJs stopped. Later, DJs continued as the bands played and thus bands could not be heard from the Common Area or outside. DJs would often announce the bands. This, or the DJs playing something popular, could prompt lots of people who were outside in the car park to simultaneously try and get access to the Common Area.
} 


\section{Accept}

The act of accepting, and in particular paying a fee where required, is the simplest method of a 'desirable' attendee gaining access to an occasion. If the venue is overcapacity the doorperson will not allow an attendee to enter. Attendees may complain and even feel angry, but they are likely to understand the regulatory framework that ensures people's safety by avoiding overcrowding. Where there is need for an invite or fee (the latter potentially represented by some form of ticket, electronic or otherwise) and none is produced, the attendee will be refused entry. The doorperson can also prohibit entry to an attendee on the basis of their 'undesirability'. In all cases the authority of the doorperson will not be challenged by the attendee.

The act of visible acceptance by the attendee lends legitimacy to the organisers and the doorperson. In particular, when an invite or fee is required, observing this requirement sets in place a practice that being invited or paying is the legitimate thing to do. As Garfinkel states the act of paying and enforcing is "instructably observable and instructably reproducible" (2002: 164). This also co-creates the authority of the doorperson. Where a fee is required it may be needed to cover the costs of the occasion: the act of paying legitimises this means of entry and a doorperson or doorpeople's method of taking payment.

\section{Provide an 'Exception'}

The following categories of fee avoidance all respect the authority of the boundary and require the doorperson to make an exception. The doorperson may choose to 'provide an exception' to the need to stay within capacity, or have an invite/fee. This provision could be unprompted, or it could result from the attendee seeking an exception. When the attendee seeks an exception, they acknowledge the authority of the doorperson to restrict access; the doorperson must then assess the legitimacy of the attendee's claim.

Sanctioned rule breaking is a visible way to transgress a boundary and as Garfinkel (2002) notes an exception requires accountability. Here, the doorperson has to acknowledge that, in these particular circumstances, the application of the access restriction is unreasonable. As a result, the doorperson is then accountable on whether or not an exception is made, even if just to say the restriction 'applies to everyone'. Where an attendee seeks an exception, they use the methods outlined in the relevant section of Table 2. Successfully gaining an exception requires particular degree of skill on the part of the attendee, that is, enough skill to enable the doorperson to accept the attendee's claim as legitimate.

\section{Attendee Identified as 'Guest'}

In the case where a venue is over-capacity, or where a fee is mandatory, it may still be possible for people to gain access by being identified as a 'guest'. If an invite is required, every attendee is essentially a guest, although where a ticket is needed there 
is still potential to use other methods (particularly those in "Attendee Pretends to Have Accepted" section). An attendee on the guest list ${ }^{11}$ can say that they have a 'guesty'. There was no guest list at the mega party because the large number of bands would have meant lots of guests, potentially making the night economically unviable. However, the presumption that there would be a list meant this was still invoked as a means of entering. Guests may be 'prearranged' and have their names on a guest list, or 'on the spot' where door staff just let people in. Both types are explained below.

A guest list is often kept at the entrance and this list requires the doorperson to determine whether or not the 'guest' categorisation is legitimate. ${ }^{12}$ People have claimed to be someone else-saying the name of guests that they would expect to be listed (refer to "Attendee Recategorised (or Not) as Worker or Guest" section). Guests may have some role in making the social occasion happen, where they have a role, an invitation to the occasion or fee-wavier in lieu of payment for 'work' undertaken is normal.

Prearranged guests will have some association with a worker, although this may be once removed where a guest is given an additional place $(\mathrm{a}$ ' +1 '). Guest lists can be elaborate - the club 'Optimo' (with a regular night in Glasgow, 1997-2010) had levels of guest ranging from those who paid nothing to only $£ 1$ off the total charge: arguably as the concession diminished so did the kudos.

In addition to a pre-arranged list, workers can make someone an 'on-the-spot' guest. People may be automatically guestlisted when associated with another venue e.g. staff at Nice 'N' Sleazy (a bar and venue in Glasgow that is open late) often get free entry into other clubs and bars by virtue of being fellow workers in similar types of venue or as a result of associations between the owners. This could be described as an informal privilege; although not working for the same organisation or in the same location, there is recognition that they are a co-worker or colleague. In relation to other staff, the guest list provides the opportunity to acknowledge those with shared tastes and build identities in common (Brown and Laurier 2014).

In addition, status may also play a role. A 'known' or famous person may automatically assume guest status because their celebrity presence is anticipated to add prestige: they lend their symbolic status through their material presence in exchange for the free entry. At the mega party, as there were no 'guests,' someone from an internationally known Glasgow band was surprised to be asked to pay and claimed to have no money. The response, 'you can pay with a card' was met with a blank stare.

\footnotetext{
${ }^{11}$ The guest list is represented in popular culture. For example, Kicks Like A Mule, The Bouncer (Halkes and Russell 1992) contains the lines "Your names not down you're not comin in" "Not tonight you're not on the list".

${ }^{12}$ Rather than offering a universal classification we provide a description of what constitutes a legitimate guest in this situation. For example, in gatherings such as wedding receptions, everyone is a guest because there is no fee, and if not a guest, all other legitimate categories must collectively come under the banner of 'workers'. However, the wedding requires a more complex formulation of what constitutes a guest, because weddings have legitimate uninvited onlookers/well-wishers and if held in a religious building such as a church or temple the congregation are guests in the House of God, which is extended through the associated clerics.
} 
An obvious example of where someone gets an on the spot guesty is when a doorperson identifies that the prospective attendee is 'attractive' in some way, this depends on the scene and whether the person could be viewed as "fitting in" (Goffman 1963: 11). It is judicious of the doorperson to let in particular people if they somehow reflect or build the aspirations of the venue or the particular night. This can be gendered, some venues let woman in for free or for a reduced cost; conversely, I have never been made aware of a similar policy for men. ${ }^{13}$

Workers' identification of attendees as guests enables them to generate authority on the basis of implementing a restriction. Where guests are 'pre-invited' or 'on-thespot,' the doorperson becomes a substitute 'host' whether their actions are actually related to the intentions of the organiser of the night or the owner. Guests are recognised as people whose presence (whether directly or by proxy) is desired at the venue, with judgement of who or what is desirable made by organisers and doorpeople. ${ }^{14}$ In the case where a fee is charged, not paying, through the category of being made a guest, is worth far more than the fee's financial cost. It is evident that, even where a fee is highly affordable, being seen not to pay, being a guest, is visually (and symbolically) important for guests and organisers.

This paper now focuses on where people understand they should have an invite or pay a fee but attempt (whether successfully or unsuccessfully) to gain access without being invited or paying. Successful avoiders receive (some of) the same benefits as guests, but require no association with the workers: they imperceptibly circumvent the differentiation between people created by the boundary.

\section{Attendee Recategorised (or Not) as Worker or Guest}

Attendees may be recategorised by the doorperson as a worker or a guest (due to their association with workers) in cases where the venue is over-capacity, or where a fee is required. The attendee must be viewed as someone who is within the category of person that should be let in. Someone may be identified as being in a band or claim to be in a band-and this may be supported by people in the band. At the mega party someone supported a claim from their friend that the friend was going to be playing and therefore the friend got in for free. That band was the last band to play, thus I saw the set and it was evident that the friend was not playing- the friend's absence made visible a possible deception.

People often come in and claim to be a friend of a worker, i.e., the owner/ sound man/ band and this supports their recategorisation as 'guest'. This may or may not

\footnotetext{
13 This raises an important topic: As Massey (1994: 180) observes "gender is of significance to geographical constructions of space and place" and gender composition of doorpeople and the attendees can affect the dynamics of the relationships between workers and attendees (as acknowledged by Hobbs et al. 2007). However, to discuss this is sufficient detail would require moving away from the intention of this paper to outline methods of entering.

14 'Desire' does not necessarily mean that the guests are actually really wanted-there may be a requirement for certain people to be invited (e.g., an estranged family member may be invited to a wedding) and it depends on how exclusive the venue is. Goffman (1963/1966: 10-11) discusses in detail reasons that certain individuals may be excluded from specific places on the basis of their being 'undesirable'.
} 
be legitimate. At the mega party a woman came up and asked for one of the people that was working in the other room. Rather than pay she then said she would call him; as there was no guest list he came out and paid for her. The doorperson can also identify someone within this category, particularly if they are associated with an important worker, such as the manager.

Difficulties arise because what constitutes a worker may be unclear. Although there were doorpeople, organisers and band members at the mega party, it was also possible to make someone a worker on the spot. Someone could be attending the occasion and be asked to help shift equipment. This differs starkly from other situations, for example large scale commercial music events where everyone has a clearly assigned role-from the official security company employed to police entry and security, to band members and other staff-who are given differentiated identity passes. At the mega party the community co-produce the event in such a way that some roles are interchangeable and fluid. Recategorising is a useful device which allows the doorperson to maintain the legitimacy of the invite/fee by quickly assessing where someone should be given access. It maintains the legitimacy of the invite/ fee through the co-production of a recategorisation-both parties negotiate to determine what category applies to the attendee.

\section{Bargaining to Gain a Concession}

In the case where a fee is charged, the doorperson can choose whether or not to offer a concession. Attendees' claims for why a concession should be provided are often based around three different lines of argument related to: the personal circumstances of the attendee; the possibility of a group discount for two or more people; or on the basis of an incomplete service. These three different categories can also be used in combination.

Attendees may attempt to bargain for a concession in terms of their personal circumstances particularly when a flat fee is charged and concessions not explicitly catered for. Concession seekers use commonly understood categories such as unemployed or student or base their claim on comparatively vaguer conditions such as not having much money. This activity recognises the authority of the doorperson because the attendee is acknowledging the charge but claiming for a specific reason that a discount is appropriate. Such requests play on a shared understanding of 'paying on the basis of ability to pay'.

In contrast, when people arrive very late, and they have missed some of the entertainment (e.g., support bands or acts) they may claim that the service they are receiving is 'incomplete' and the fee should be lowered. This tactic is drawing on a logic of market exchange in which a reduced service commands a similarly reduced price. ${ }^{15}$ However, such logic can be more complex. For example, if two or more

\footnotetext{
15 Anecdotally, I have heard of people retrospectively trying to get money back at the end of a night after viewing most of the entertainment. Two of my friends came to the second mega party claiming to have insufficient funds to enter and therefore I paid part of their fee. My friends may have lacked funds but this action was probably a test of my resolve.
} 
people are attempting to gain access, they may claim that it would be in the interests of the venue/ organisers to give a group discount. Where the venue is not busy their presence could make the venue look more desirable - in this case attendees invoke a supply and demand argument.

\section{Attendee Requests Exception to Access a Resource or Person}

There are other circumstances (beyond those already described in "Attendee Identified as 'Guest," "Attendee Recategorised (or Not) as Worker or Guest" and "Bargaining to Gain a Concession") which require an exception to be made in cases where the venue is over-capacity or where a fee is required. The attendee may seek an exception to access, a resource (such as the toilets), a worker or another attendee. During the mega party, there were a large group of about eight people outside and some of them were there for the whole time I was at the door. Two members of this group claimed that they needed to get in to use a resource, the toilet. However, this claim was judged illegitimate because there were portaloos ${ }^{16}$ outside. They were not let in.

An attendee may be, or claim to be, associated with a worker and is thus recategorised as guest (thus there is potentially some overlap with "Attendee Recategorised (or Not) as Worker or Guest"). An exception being made as a result of the prospective attendee needing to speak to another attendee who is inside. For example, that they have to see them for some reason such as 'drop off something with them,' 'tell them something's happened'. The prospective attendee offering to leave belongings at the door, such as a bag, makes this claim seem more legitimate. The doorperson may, or may not, require the offer to be carried out: belongings left at the entrance may clog it up.

Claims to get access to see someone may be legitimate and the doorperson has to determine whether or not the attendee should be in a different category, whether or not an exception to the access restriction should be made. Once, when I was working at a door someone (who, incidentally, tried to pay) got in for free because they had clearly been attacked and were traumatised and needed to see a relative who was inside.

In all cases, the doorperson must assess whether or not an exception to the access restriction should be approved. If a claim is made by an attendee, the doorperson has to make a moral judgement about the legitimacy of that claim. Not allowing someone to use a toilet seems wrong, but the presence of portaloos means this claim holds no moral weight: the illegitimacy of the claim is also evident leaving prospective attendees with no room for negotiation. A doorperson visibly making exceptions has potential to generate more grounds on which exceptions should be made. However, where claims are legitimate making an exception can make the doorperson's authority stronger because it maintains a sense of agreed fairness, or the coproduction of what is deemed reasonable.

${ }^{16}$ Portable toilets. 


\section{Attendee Pretends to Have Accepted}

Where the 'attendee pretends to have accepted,' the attendee is fully aware that a payment is expected, but opt for not paying via some form of pretence in an attempt to imperceptibly avoid the charge. Therefore, the doorperson must be vigilant to identify the use of these methods of entering. The attendee may generate a pretence of legitimacy without use of a signifier - that is a ticket or mark which denotes invitation, fee payment and/or prior entry. However, the attendee could also attempt to gain signifiers of legitimacy.

\section{Pretence of Legitimacy Without a Signifier}

Where people generate pretence of legitimacy, without something that denotes invitation, payment or prior entry, they make it appear as if they are not quite sure whether or not there is an access restriction. The attendee walks in as if they were just meant to be there-looking blank. Two potential attitudes underpin this action, ignorance of an access restriction, and the communication that they have already entered the venue earlier in the evening. The former may or may not be legitimate; the latter is always illegitimate if the attendee has not previously had access.

This is a very successful method; I have used it many times and have rarely been questioned-it works well singly or with a group. If the doorperson challenges the pretender they can easily claim 'I didn't realise'. Paradoxically, if this method is used where there is a very obvious border it can lend this approach a greater appearance of legitimacy. A large number of people tried this at the mega party, but because I remembered who had gone in and out and checked stamps (Fig. 2) my interpretation is that the overall collective attempt was relatively unsuccessful. There is also a nuanced version of this method, where the area around a door is very busy, the prospective attendee may be able to work their way in and through a crowded entrance without the awareness of the doorpeople.

Where an attendee is illegitimately attempting to express that they have already accessed the venue, it works best if the attendee looks as if they have just been out briefly, achieved by not carrying lots of things such as coats and bags. However, in the case of the mega party it was BYOB and therefore people were carrying alcohol including boxes of beer and due to the lack of a cloakroom many people had belongings with them.

A variation of this method is where the attendee carries equipment to make it seem as if they are in (or are associated with) a band that is playing. Someone may have given them equipment for this purpose or they may have been practicing before and have something portable with them (e.g., a guitar). Such actions support an implicit claim to entitlement to recategorisation as worker. This could be successful in situations such as the mega party where practically, with 22 bands, the people doing the door are unlikely to know everyone well. One person tried to do this illegitimately at the mega party, carrying in a guitar and trying to walk past the 
doorpeople without paying. When challenged they admitted that they were not playing that night. ${ }^{17}$

\section{Acquiring Signifiers of Legitimacy}

When someone enters a social occasion a number of different things can be used to indicate that they are there legitimately or have already been in. For example, the person could be recognised by those at the door, they may have a ticket (that could be electronic) — which may be accompanied by or replaced by a wristband or stamp, or by having a mark made (normally on one hand or wrist) using a pen. Therefore, if an attendee can acquire the appropriate signifier of legitimacy, either directly or by making a facsimile, they may be able to illegitimately gain access to the occasion.

Obviously, this is difficult or exceptionally elaborate to fake if you need to be known by the doorperson. However, tickets or wristbands may be swapped over; this can happen outside the venue or by an attendee retrieving one from inside and giving it to someone outside. Tickets can also be forged in advance of the occasion, for example a friend regularly photoshopped preview tickets for the Edinburgh Film Festival. Wristbands can be made from white or coloured paper or other materials cut to the right size.

In the case where a mark is made on a hand the method varies with the type of identification needed. Where pens or stamps are used the marks can be copied. People have been known to take a selection of coloured pens out to clubs to fake the mark. Where a crude X or other simple mark is used, forging is not necessarily difficult or sophisticated. Additionally, depending on the ink used, a stamp can be licked and then pressed onto the hand of another person (as illustrated within the film Slacker 1991). The weak mark can be retained or the stamp can be coloured in.

At the mega party a stamp was used, Fig. 2. This is not symmetrical and has writing on it. Therefore, when one person licked the stamp on their hand and pressed their hand again onto another, a mirror image appeared, an obvious 'fake'. During the night I observed two very clear attempts at forgery by drawing the stamp.

The first was where a smudgy mark on a hand had been outlined. There was a pen in the pocket of the bearer of the mark and it looked like the pen on their hand. I let them in-when they passed the door later I said 'you faked the stamp' and they said that they had but that they had borrowed the pen from someone else and 'couldn't believe I'd a similar pen in my pocket'. By admitting to the forgery the attendee laid claim to the skill, making it visible. I talked about the low entrance fee and the need for people to pay to enable the bands to cover their costs. They disappeared and about half an hour later paid the $£ 5$ fee. This retrospective action demonstrates acknowledgement of a shared understanding that bands deserve to have their expenses covered.

The second occasion was someone I recognised and knew had not paid-again a smudgy mark on the hand and the outline drawn in biro this time. This person had not paid in and so was turned away. Although later in the evening (after I left the

\footnotetext{
17 In this case the attendee could have lied and then it would be at the discretion of the doorperson whether or not to believe their claim.
} 
door at 3 a.m.) I saw them wandering around. Therefore, they had clearly waited outside, determined to get into the venue.

A large group to my right (as I was facing the door) were clearly copying the stamps - they did this by one person coming in to pay and then walking out againthen waiting for a long period-then another one repeating this action. Therefore, one or more members of a group can act as 'scouts' gathering information about "terrain up ahead" (as Reeves et al. 2009: 219 discuss in relation to online gaming). Although they had got there early at 9 p.m., and had tried several forms of avoidance, it was 2 a.m. by the time all had paid to get in-members of the group also used the approaches outlined in "Attendee Requests Exception to Access a Resource or Person".

Therefore, people may wait for long periods of time-demonstrating a determined effort to circumvent the access restriction by not paying, even where the entry fee is relatively inexpensive. The process of forgery and waiting are collective experiences of the attendees, with payers helping the avoiders in a shared game. Obviously, in part, this was possible because the occasion continued in the car park. In this case, a doorperson is required to be vigilant otherwise it would be easy for attendees to gain access illegitimately.

\section{Open Disregard by Attendee}

Where people openly disregard the access restriction, they run at the transitional space of the entrance and force their way in, they 'breach' the entrance. This can be done in a group or singly. To work, it requires the venue to be busy and people risk being pursued by workers and then thrown out. Breaches happened twice at the second mega party: first, where the closed side of the door was forced open and then a group of people ran in (it was difficult to control and see what was happening); second, when someone who was very intoxicated ran straight into me, I grabbed them but could not stop them entering while maintaining my place at the door.

Breaching, as with Garfinkel's (1967/1984a) use of the term, temporarily affects a breakdown of social order. However, in contrast to Garfinkel's experiments, such breaching was not (to my knowledge) instigated to consciously inform analysis. The breacher demonstrates their understanding that access is restricted-running at the door is an illustration of this understanding. They first visibly break the restriction and second, risk attracting negative sanctions, such as being thrown out. The breachers' action differ from the other formulations of fee avoidance because their approach is an overt interruption to the accepted forms of interaction.

The breacher's challenge invites those involved in managing the occasion to reinstate order. If doorpeople are successful at stopping a breacher entering, the authority of the boundary is visibly produced for all to see-by tackling the breacher the doorperson makes a visible, physical, demonstration of their commitment to the border and to the community. However, if it fails, it can bring the credibility and ability of the doorperson into question. Potentially, where a breacher or breachers use unreasonable force it can engender sympathy for the door person being overpowered by physical violence. Breaching is hostile and disregards any understanding of 
shared community values. What breaching makes evident is that other methods of gaining access acknowledge restrictions whilst covertly getting around them.

\section{Discussion}

All of these methods demonstrate that the space of the entrance, and the process of entering, is accomplished through the interaction between attendees and workers. However, when attendees pretend to have accepted or openly disregard the access restriction they could be viewed as undermining the idea that payment should be made. Such undermining differs from that previously documented (Bifo 1979; Garfinkel $1967 / 1984$ b) because the authority being undermined is not directly linked to an organisation that is supported by the legal apparatus of state. Someone 'forging' a stamp to get into the mega party is not going to face criminal charges.

What is being undermined depends on who organised the occasion. In the case of the mega party this was a group of people attempting to cover the costs of the entertainment. Therefore, widespread fee avoidance in this instance highlights a potential contradiction in the attitudes of those attending. People generate their identity via the act of avoidance whilst simultaneously undermining the institution (the occasion) upon which that identity relies.

The person who came back to pay after being alerted to the circumstances surrounding the mega party shows some recognition of an understanding that the fee is necessary. However, the co-operation between fee-payers and avoiders illustrates a widespread approval of 'resisting the fee'. There appears to be an on-going tension between people's desires to gain entry without paying and their support for the occasion, in this case by paying a fee: much of the community is committed to two competing ideals.

Those that acquire signifiers of legitimacy are not necessarily visible either to workers or other attendees. As with the attendees that generate a pretence of legitimacy, success at catching avoiders and turning them away demonstrates the doorperson's commitment. Avoiders succeed in deception where it is invisible to the doorperson. However, attendees make avoidance visible to other people by narrating how they have got around the access restriction. This deception may be facilitated by local knowledge, building a community of those circumventing the fee.

The legitimacy and perceived fairness of the restrictions is both eroded and strengthened by the ability of the doorperson to make an exception. Thus, the grounds for an exception have to be carefully assessed, otherwise too many exceptions could undermine the doorperson's authority. This authority must be maintained to control the occasion. Exceptions are needed to avoid extreme authoritarianism, allowing for sensitive gestures such as letting someone in for free when they had been attacked. Thus, permitting an access restriction to be challenged can extend the health of the community.

The method of breaching demonstrates an awareness of the restriction and a deliberate and very visible attempt to circumvent the space of the entrance. Whereas other illegitimate methods require a greater degree of skill than accepting or disregarding (that is, breaching) because attendees must pay close attention to the existing rules, this involves: prior experience of similar occasions; knowing what type 
of excuse gets turned into making an exception; predicting a doorperson's response; potentially acting the part of someone else. Arguably, the two least visible or invasive methods of illegitimately circumventing the access restriction, where attendees pretend to have accepted the restriction, will always be the most powerful or successful. Far from undermining the role of the organisers, those resisting the border through illegitimate methods gain access whilst a semblance of order is maintained.

Acknowledgements Thanks to: the three anonymous reviewers together with Barry Burns, Susan Fitzpatrick, Eric Laurier and Katherine MacBride for detailed comments on earlier drafts of this paper; Marie-Avril Berthet, Evgenij Belikov, Sian Robinson Davies and Clare Stephenson for reading the paper and making helpful suggestions; Winning Sperm Party (particularly Rob Alexander and Chris White), Croc Madame vs Croc Monsieur (Liam Casey and Laurie Pitt); and, the large number of people with which the first author has discussed or explored this topic, or both. The first author's writing is made possible by the kindness of Margaret McLauchlan.

Open Access This article is distributed under the terms of the Creative Commons Attribution 4.0 International License (http://creativecommons.org/licenses/by/4.0/), which permits unrestricted use, distribution, and reproduction in any medium, provided you give appropriate credit to the original author(s) and the source, provide a link to the Creative Commons license, and indicate if changes were made.

\section{References}

Bakhtin, M. (1994). Carnival ambivalence: Laughter, praise and abuse. In P. Morris (Ed.), The Bakhtin Reader (pp. 206-226). London: Edward Arnold.

Bifo, F. B. (1979/2007) Anatomy of autonomy. In S. Lotringer (Ed.), Autonomia: Post-political politics (pp. 148-171). Los Angeles: Semiotext(e).

Brown, B., \& Laurier, E. (2014). Word of mouth: Products, conversations and consumption. Consumption Markets \& Culture,17(1), 29-49. https://doi.org/10.1080/10253866.2012.675827.

Brunet-Jailly, E. (2007). Introduction: Border security and porosity. In E. Brunet-Jailly (Ed.), Borderlands: Comparing border security in North America and Europe (pp. 1-18). Ottawa: University of Ottawa Press.

Coulon, A. (1995). Ethnomethodology. Thousand Oaks: Sage Publications.

Crabtree, A. (2000). Remarks on the social organisation of space and place. https://www.cs.nott. ac.uk/ axc/work/JMBv1.pdf. Accessed July 18, 2018.

Fintoni, A., \& McLauchlan, A. (2018). Assembling the dance: Reggae sound system practices in the United Kingdom and France. The Senses and Society, 13(2), 163-178. https://doi.org/10.1080/17458 927.2018.1483655.

Garfinkel, H. (1967/1984a). Studies in ethnomethodology. Cambridge: Polity Press.

Garfinkel, H. (1967/1984b). Studies of the routine grounds of everyday activities. In H. Garfinkel (Ed.), Studies in ethnomethodology (pp. 35-75). Cambridge: Polity Press.

Garfinkel, H. (2002). Ethnomethodology's program: Working out Durkheim's aphorism. Oxford: Rowman \& Littlefield.

Garfinkel, H., \& Stoller., T.J. (1967/1984). Passing and the managed achievement of sex status in an intersexed person, part 1. In H. Garfinkle (Ed.), Studies in ethnomethodology (pp. 116-185). Cambridge: Polity Press.

Goffman, E. (1963/1966). Behavior in public place: Notes on the social organization of gatherings. New York: The Free Press.

Gold, R. L. (1958). Roles in sociological field observations. Social Forces, 36(3), 217-223. https://doi. org/10.2307/2573808.

Halkes, N., \& Russell, R. (1992). The Bouncer. London: Tribal Base Records.

Hobbs, R., Hadfield, P., Lister, S., \& Winlow, S. (2002). 'DOOR LORE': The art and economics of intimidation. British Journal of Criminology, 42, 352-370. https://doi.org/10.1093/bjc/42.2.352. 
Hobbs, R., Hadfield, P., Lister, S., \& Winlow, S. (2003). Bouncers: Violence and governance in the nighttime economy. Oxford: Oxford University Press.

Hobbs, R., O’Brien, K., \& Westmarland, L. (2007). Connecting the gendered door: Women, violence and doorwork. The British Journal of Sociology, 58(1), 21-38. https://doi.org/10.111 1/j.1468-4446.2007.00137.x.

Johnson, J. (1988). Mixing humans and nonhumans together: The sociology of a door-closer. Social Problems, 35, 298-310. https://doi.org/10.2307/800624.

Latour, B. (1992). Where are the missing masses? The sociology of a few mundane artifacts. In W. Biker \& J. Law (Eds.), Shaping technology, building society: Studies in sociotechnical change (pp. 225228). London: MIT Press.

Malbon, B. (1999). Clubbing: Dancing, ecstasy and vitality. Abingdon: Routledge.

Massey, D. (1994). Space, place and gender. Cambridge: Polity Press.

Metcalfe, A. W., \& Ferguson, L. (2001). Half-opened being. In J. May \& N. Thrift (Eds.), Timespace (pp. 240-261). London: Routledge Press.

Neyland, D. (2006). The accomplishment of spatial adequacy: Analysing CCTV accounts of British town centres. Environment and Planning D: Society and Space, 24, 599-613. https://doi.org/10.1068/d384t.

Raffel, S. (1999). Revisiting role theory: Roles and the problem of the self. Sociological Research Online, 4(2), 1-16. https://doi.org/10.5153/sro.217.

Raffel, S. (2007). Self-reflective rule-following. Culture and Organization, 13(4), 327-335. https://doi. org/10.1080/14759550701659037.

Reeves, S., Brown, B., \& Laurier, E. (2009). Experts at play: Understanding skilled expertise. Games and Culture, 4(3), 205-227. https://doi.org/10.1177/1555412009339730.

Sack, R. D. (1986). Human territoriality: Its theory and history. Cambridge: Cambridge University Press.

Simmel, G. (1994). Bridge and door. Theory, Culture and Society, 11, 5-10. https://doi.org/10.1177/02632 7694011001002.

Slacker. (1991). Directed by Richard Linklater [Film]. Los Angeles: Orion Classics.

Wedding Crashers. (2005). Directed by David Dobkin [Film]. Los Angeles: New Line Cinema.

Weilenmann, A., Normark, D., \& Laurier, E. (2014). Managing walking together: The challenge of revolving doors. Space and Culture, 17(2), 122-136. https://doi.org/10.1177/1206331213508674.

Publisher's Note Springer Nature remains neutral with regard to jurisdictional claims in published maps and institutional affiliations. 